\title{
The Effects of Residual Blood of Carcasses on Poultry Technological Quality
}

\author{
Bourbab Mohamed*, Idaomar Mohamed \\ Laboratory of Biology and Health, Faculty of Science, University Abdelmalek Essaadi, Tétouan, Morocco. \\ Email: *bourbab.m@gmail.com
}

Received July 23 ${ }^{\text {rd }}$, 2012; revised September $7^{\text {th }}$, 2012; accepted September $15^{\text {th }}, 2012$

\begin{abstract}
The objective of this work is to show the effect of residual blood on the quality of chicken meat. Work based on the hypothesis that increasing the concentration of residual blood would explain the observed quality degradation by several authors. Lots of chickens are killed with two different types of slaughter: slaughter without stunning for a maximum flow of blood or bleeding perfect PS, shooting seals slight lead to keep almost all blood from the carcass or bleeding IS flawed. To prove the residual blood factors that are responsible for high $\mathrm{pHu}$ level and high values of $\left(\mathrm{L}^{*} \mathrm{~A}^{*} \mathrm{~B}^{*}\right)$ in poultry, this study compares the pHu level and values of $\left(\mathrm{L}^{*} \mathrm{~A}^{*} \mathrm{~B}^{*}\right)$ in poultry both perfectly and imperfectly bled. Samples from imperfectly bled carcasses show a high value average number of $\mathrm{A}^{*}=12.68$ and $\mathrm{B}^{*}=16.85$; and $\mathrm{L}^{*}=$ 54.09 vs the average number of $\mathrm{A}^{*}=8.50$ and $\mathrm{B}^{*}=14.43$ and $\mathrm{L}^{*}=50.27$. At $3^{\circ} \mathrm{C}$ storage temperature, the average $\mathrm{pHu}$ of perfectly bled poultry was $(5.7)$ which was significantly $(\mathrm{P}<0.01)$ lower than the average $\mathrm{pHu}$ of imperfectly bled poultry (6.08). At $7^{\circ} \mathrm{C}$ storage temperature, the average pHu of perfectly bled poultry was (6.07) which was significantly $(\mathrm{P}<0.05)$ lower than the average $\mathrm{pHu}$ of imperfectly bled one (6.27). We found out the effect of season on the results of pHu measures, so we conducted aanalysis of pHu in summer and winter. Residual blood of the poultry is responsible for high values of $\left(\mathrm{L}^{*} \mathrm{~A}^{*} \mathrm{~B}^{*}\right)$ and high values of $\mathrm{pHu}$ therefore the deterioration of the poultry Colour.
\end{abstract}

Keywords: Meat Quality; Residual Blood; Poultry; Meat Colour; Meat pHu; Perfectly Bled (PS); Imperfectly Bled (IB)

\section{Introduction}

The objective of this work is to show the effect of residual blood on the quality of chicken meat, when cattle are slaughtered, up $4.5 \%$ of body weight is removed with bleeding [1,2]. Even with effective bleeding only $50 \%$ of whole blood is removed. The different muscles preserve the blood more or less depending on their nature [3]. Chickens are losing between $35 \%$ and $50 \%$ of total body blood during the bleeding phase [4]. $60 \%$ of total blood volume is lost during bleeding of animals and from $20 \%$ to $25 \%$ in the viscera and the remaining $15 \%$ to $20 \%$ remaining in the bones and not more than $10 \%$ remains in the muscles [5].

This residual blood in the carcass is often associated with a meaty flavour and decreased shelf life [6]. Therefore excessive haemorrhaging caused by different stunning and slaughter techniques can increase haemoglobin content in the muscle that can decrease shelf life by increasing oxidation [6].

As the water retention capacity of the pectoral muscle and thigh significantly increased with the $\mathrm{pH}$ of the meat

${ }^{*}$ Corresponding author.
(Dunn et al., 1993 [7], Cornforth, 1994 [8,9] Northcutt et al., 1994 and [10] Allen et al., 1997 in chicken; [11] Barbut \& Mittal, 1993 in turkey): the case of meat Imperfectly grooves that have a high $\mathrm{pH}$ and high losses of technological quality parameters with significant correlations in accordance with work (Barbut, 1993 and 1996 [12]; Fletcher, 1999 [13]; Van Laack et al., 2000 [14]).

From these observations postulated by different authors, we formulated our hypothesis, based on the fact that the presence of residual blood in the carcasses would result in an increase of microorganisms and $\mathrm{pH}$ in carcasses imperfectly bled over carcasses perfectly bleeding leading to quality degradation. The work is based on the assumption that increasing the concentration of residual blood would explain the quality degradation observed by several authors [15-17,19,23]

\section{Materials and Methods}

\subsection{Choice of Chicken as Material}

The study uses poultry as biological material. The number of the muscle samples of chicken carcasses from the group designated for analysis of $\mathrm{pH}$ is 220 ; the number 
of the muscle samples of chicken carcasses from the group designated for analysis of color is 100 .

\subsection{Conditions of Pre-Slaughter and Slaughter}

The carcasses used to derive lots having lived the same characteristics and conditions before and after slaughter to prevent the intervention of some intrinsic factors (muscle metabolic type of the animal, genetics, age, race, sex, eating habits, etc.) and extrinsic (type of farming, housing, treatment ante-mortem handling by the farmer etc.) and other physic-chemical factors such as temperature, oxygen availability, mode of storage, and the type of lighting.

\subsection{Description of the Method of Slaughter}

Lots of chickens are slaughtered in two different ways: first, slaughter without stunning for a maximum discharge of blood, that is perfectly bled (PB) is done through an incision in the neck by hand and involves using a sharp knife to make a profound and rapid incision from the front of the throat, which at the same time cutting the carotid arteries, the trachea and jugular veins, but leaves spinal cord intact. Issued a funnel of bleeding, and plucked as soon as the animals have stopped moving. This allows a large evacuation bleeding blood.

However the second method of slaughter that we used is to kill chickens derived from lead ball on the head of the bird using a rifle with small ball of lead; this second method only allows the evacuation of very small amount of blood. The discharge of blood is done automatically without any experimental protocol.

The plucking is made by soaking the chicken in a bowl with hot water (about $50^{\circ} \mathrm{C}$ ).

\subsection{Data Analysis}

Data were statistically analysed using means and standard error of means, the effects of residual blood of carcasses on pHu was determined by student t-test and correlation coefficient matrix of meat quality by Pearson coefficient correlation, all analysis was performed by using SYSTAT 10.2 .

Version 7600.LSD values at $\mathrm{P}<0.01$ were obtained for comparison of mean values [16].

\subsubsection{Colorimetric Analyses}

In the first experiment ( $\mathrm{n}=100,50$ per treatment) samples are used to study the effect of residual blood on the color $(\mathrm{P}<0.1)$, according to the experimental plan Table 1.

Poultry colour is determined with Minolta CR 300. The Instrumental is set to measure CIE $\mathrm{LAB}^{*}$ colour values that represent lightness $\left(\mathrm{L}^{*}\right)$, redness $\left(\mathrm{A}^{*}\right)$, and yellowness $\left(\mathrm{B}^{*}\right)$. All measurements are carried out on the surface of the scallop, in an area free of obvious colour defects (over scalding, bruises, blood spots, and haemorrhages), and are often used to determine breast meat quality [19].

\subsubsection{Analysis of $\mathrm{pHu}$}

In the second $(\mathrm{n}=260,130$ per treatment) samples are used to study this effect on pHu, according to two experimental designs (Table 2).

\subsection{Measurement Site}

The $\mathrm{pH}$ measurement is made inside the muscles of the chest and thigh to reflect the heterogeneity of the $\mathrm{pHu}$ carcasses. We evaluated the effects of residual blood of carcasses on the technological quality $(\mathrm{pHu})$ meat by four experiments. These experiments are based on treatment formulated in terms of method of slaughter. We performed each experiment with meat perfectly bled and bled meat imperfectly. The carcasses are stored at $3^{\circ} \mathrm{C}$ or $7^{\circ} \mathrm{C}$ before each measurement.

In The first experiment, before evaluation, the samples were stored at $3^{\circ} \mathrm{C}$; we evaluated the growth of $\mathrm{pHu}$ of the perfectly bled poultry with the imperfectly bled one, for the comparison between the changes of $\mathrm{pHu}$ in the two substrates.

In the second experiment, we realized the same comparison but the samples were stored at $7^{\circ} \mathrm{C}$. Increases in the average summer $\mathrm{pHu}$ led us to see the effect of season on the results, that's why we made the same comparisons in the summer (Experiment 3, and Experiment 4). In the 4th experiment we increase the number of sample to 100 to see the influence of the change in the number of samples, according to experimental plan (Table 2).

pH measurements are made by $\mathrm{pH}$ meter HI 99163;

Table 1. Experimental general plan.

\begin{tabular}{|c|c|c|c|c|c|c|}
\hline \multirow{2}{*}{$\begin{array}{c}\text { Measuring equipment } \\
\text { Slaughter type }\end{array}$} & \multicolumn{6}{|c|}{ Minolta colorimeter CR 300} \\
\hline & & $\mathrm{PB}$ & & & IB & \\
\hline Measured parameters & $A^{*}$ & $\mathrm{~B}^{*}$ & $\mathrm{~L}^{*}$ & $\mathrm{~A}^{*}$ & $\mathrm{~B}^{*}$ & $\mathrm{~L}^{*}$ \\
\hline $\mathrm{n}$ & & 50 & & & 50 & \\
\hline
\end{tabular}

Abbreviations: $\left(\mathrm{L}^{*}\right)$ lightness; $\left(\mathrm{A}^{*}\right)$ redness; $\left(\mathrm{B}^{*}\right)$ yellowness; $\mathrm{n}$ : Number of samples; PB: Perfectly bled poultry; IB: Imperfectly bled poultry; NB: The term imperfectly bled was used by Hess (1968) [18]. 
Table 2. Analysis of pHu experimental general plan.

\begin{tabular}{|c|c|c|c|c|c|c|c|c|}
\hline Season & \multicolumn{4}{|c|}{ In the winter } & \multicolumn{4}{|c|}{ In the summer } \\
\hline C. C. T & \multicolumn{2}{|c|}{$3^{\circ} \mathrm{C}$} & \multicolumn{2}{|c|}{$7^{\circ} \mathrm{C}$} & \multicolumn{2}{|c|}{$3^{\circ} \mathrm{C}$} & \multicolumn{2}{|c|}{$7^{\circ} \mathrm{C}$} \\
\hline Number of experiments & \multicolumn{2}{|c|}{1} & \multicolumn{2}{|c|}{2} & \multicolumn{2}{|c|}{3} & \multicolumn{2}{|c|}{4} \\
\hline Type of slaughtering & PB & IB & PB & IB & PB & IB & PB & IB \\
\hline Number of carcasses samples & $\mathrm{n}=20$ & $\mathrm{n}=20$ & $\mathrm{n}=20$ & $\mathrm{n}=20$ & $\mathrm{n}=20$ & $\mathrm{n}=20$ & $\mathrm{n}=100$ & $\mathrm{n}=100$ \\
\hline
\end{tabular}

n: The number of samples; PB: Perfectly bled poultry; IB: Imperfectly bled poultry; C. C. T: Conservation carcass temperature before each measurement.

Portable $\mathrm{pH}$ probe with penetration/temperature was used to measure the $\mathrm{pH}$ of 260 samples of carcasses by inserting depth of the muscle approximately $2.5 \mathrm{~cm}$, at $24 \mathrm{~h}$ post-mortem.

\section{Results and Discussion}

\subsection{Colorimetric Analyses}

The effect of residual blood of carcasses on colour is reported in (Table 3 ). The samples that are imperfectly bled show a high value of $A^{*}=12.68$; and $B^{*}=16.85$; with a pale colour $\mathrm{L}^{*}$ (54.09).

The results of excessive bleeding caused by different stunning techniques and by imperfect slaughter increase the haemoglobin concentration in the muscle and decrease the organoleptic quality. The increase in red and yellow colour causes the pink colouration which is due to the imperfectly bleeding and which may lead to a downgrading of the carcasses. Samples from imperfectly bled carcasses also show a high value of $\mathrm{L}^{*}$ (54.09) which produce a pale colour. These results are consistent with the observations of many authors [6,20-23] in addition to biological factors reported by several authors [23-26] (genetic type of chicken) and the evolution time postmortem [27], the amount of residual blood is among the key factors affecting the quality of the poultry colour. Bruises, hemorrhages, and poor exsanguination efficiency can negatively affect colour of the meat and skin; these are major quality defects and are associated with undesirable discoloration and reduced shelf life [6].

\subsection{Analysis of $\mathrm{pHu}$}

The effect of residual blood of carcasses on $\mathrm{pHu}$ is reported in (Table 4). At $3^{\circ} \mathrm{C}$ storage temperature, the average pHu of perfectly bled poultry was (5.7) which was significantly $(\mathrm{P}<0.01$ ) lower than the average $\mathrm{pHu}$ of imperfectly bled poultry (6.08).

According to the work of (Gigaud V. et al., 2010) [28], variability of $\mathrm{pH}$ standards for meat chickens are between 5.7 to 6.20 (Figure 1). Normal values of ultimate $\mathrm{pH}$ ranged from 5.7 as minimum normal value and 6.25 as maximum normal value (Gigaud V., et al., 2010) [28], outside this range, and lower values to 5.7 meats have

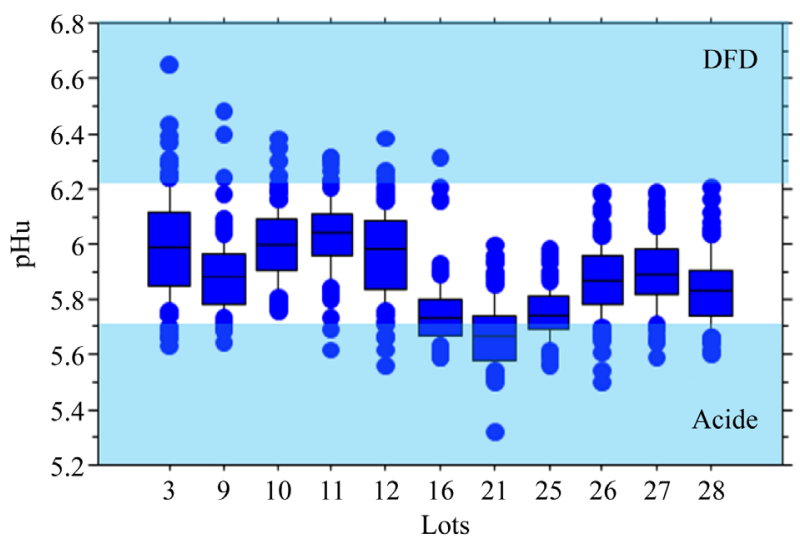

Figure 1. The variability standards pHu (Gigaud V. et al., 2010); DFD: dark, firm and dry.

defects and are called PSE (pale, soft, exudative), for higher values to 6.25 meats have defects and are called DFD (dark, firm and dry) .

At $7^{\circ} \mathrm{C}$ storage temperature, the average $\mathrm{pHu}$ of perfectly bled poultry was (6.07) which was significantly $(\mathrm{P}<$ 0.05 ) lower than the average $\mathrm{pHu}$ of imperfectly bled one (6.27).

Effect of Season on meat quality: the values for $\mathrm{pHu}$ were significantly $(\mathrm{P}<0.01)$ higher in summer than winter in two types of slaughter (perfectly bled: PB and imperfectly bled: IB) (Table 4).

These experimental results confirm the observations and assumptions made by some authors. [19,23]. A rise in the storage temperature increases the $\mathrm{pHu}$ in the two types of poultry. But the pHu of the perfectly bled meat is still minimal. The comparison of the results (Table 2) shows not only the strong relationship between carcass residual blood and the growth of the degree of $\mathrm{pHu}$, but also indicates the season effect. The lowest level of pHu is recorded during the winter. After this period the values increase to reach the highest rate in the summer, especially at $7^{\circ} \mathrm{C}$ storage.

\section{Conclusions}

After determining the quality of chicken meat by analysing the colour of different lots of chickens slaughtered at two different levels: perfect slaughter without stunning 
Table 3. Descriptive statistics of poultry colour with paired samples $t$ test.

\begin{tabular}{|c|c|c|c|c|c|c|}
\hline \multirow{2}{*}{$\begin{array}{c}\text { Variable } \\
\text { Type of slaughter }\end{array}$} & \multicolumn{2}{|c|}{$\left(A^{*}\right)$} & \multicolumn{2}{|c|}{$\left(B^{*}\right)$} & \multicolumn{2}{|c|}{$\left(L^{*}\right)$} \\
\hline & $\mathrm{PB}$ & IB & $\mathrm{PB}$ & IB & $\mathrm{PB}$ & IB \\
\hline Min & 5.02 & 8.63 & 8.51 & 9.27 & 43.01 & 45.3 \\
\hline Max & 12.62 & 17.01 & 19.34 & 21.94 & 58.51 & 66.09 \\
\hline Mean & 8.50 & 12.68 & 14.43 & 16.85 & 50.27 & 16.85 \\
\hline Ecart type & 3.5 & 2.14 & 3.97 & 2.43 & 2.59 & 4.32 \\
\hline Nombre de cases & 50 & 50 & 50 & 50 & 50 & 50 \\
\hline $\mathrm{P}$ & \multicolumn{2}{|c|}{$\mathrm{P}<0.1$} & \multicolumn{2}{|c|}{$\mathrm{P}<0.1$} & \multicolumn{2}{|c|}{$\mathrm{P}<0.1$} \\
\hline
\end{tabular}

Abbreviations: $\left(\mathrm{L}^{*}\right)$ lightness, $\left(\mathrm{A}^{*}\right)$ redness, $\left(\mathrm{B}^{*}\right)$ yellowness, $\mathrm{n}$ (number of samples); PB: Perfectly bled poultry; IB: Imperfectly bled poultry; Paired samples $\mathrm{t}$ test on $\left(\mathrm{A}^{*}\right)$ PB vs $\left(\mathrm{A}^{*}\right)$ IB with 50 cases; and $\left(\mathrm{B}^{*}\right)$ PB vs $\left(\mathrm{B}^{*}\right)$ IB with 50 cases, and $\left(\mathrm{L}^{*}\right)$ PB vs (L $\left.{ }^{*}\right)$ IB with 50 cases.

Table 4. The effects of residual blood of carcasses on $\mathrm{pHu}$, results with paired samples $\mathrm{t}$ test.

\begin{tabular}{|c|c|c|c|c|c|c|c|c|}
\hline \multirow{3}{*}{$\begin{array}{c}\text { Season } \\
\text { Experiment number } \\
\text { C. C. T. }\end{array}$} & \multicolumn{4}{|c|}{ In the winter } & \multicolumn{4}{|c|}{ In the summer } \\
\hline & \multicolumn{2}{|c|}{1} & \multicolumn{2}{|c|}{2} & \multicolumn{2}{|c|}{3} & \multicolumn{2}{|c|}{4} \\
\hline & $3^{\circ} \mathrm{C}$ & $7^{\circ} \mathrm{C}$ & $3^{\circ} \mathrm{C}$ & $7^{\circ} \mathrm{C}$ & $3^{\circ} \mathrm{C}$ & $7^{\circ} \mathrm{C}$ & $3^{\circ} \mathrm{C}$ & $7^{\circ} \mathrm{C}$ \\
\hline Type of slaughtering & PB & IB & PB & IB & PB & IB & PB & IB \\
\hline $\mathrm{N}$ of cases & 20 & 20 & 20 & 20 & 20 & 20 & 100 & 100 \\
\hline Minimum & 5.5 & 5.85 & 5.85 & 6.12 & 5.59 & 6.17 & 6.0 & 6.23 \\
\hline Maximum & 6 & 6.5 & 6.8 & 6.33 & 6.4 & 6.63 & 6.7 & 6.86 \\
\hline Mean & 5.70 & 6.08 & 6.07 & 6.27 & 6.12 & 6.42 & 6.4 & 6.6 \\
\hline Paired samples with t-test & \multicolumn{2}{|c|}{$*$} & \multicolumn{2}{|c|}{ ** } & \multicolumn{2}{|c|}{$*$} & \multicolumn{2}{|c|}{ * } \\
\hline
\end{tabular}

C. C. T: Conservation carcass temperature before each measurement; Perfectly bled: PB; Imperfectly bled IB; means are significantly different $\left({ }^{*} \mathrm{p}<0.01 ;{ }^{* *} \mathrm{p}<\right.$ 0.05). Each mean represents the mean of 20 replications; Parfaitement saignée: PS; imparfaitement saignée IB; $(p<0.01)=$ statistically significant of processed, T. c: Température de conservation avant chaque mesure; moyennes significativement différent $\left({ }^{*} \mathrm{p}<0.01 ;{ }^{* *} \mathrm{p}<0.05\right)$. Each mean represents 10 replications. vs: variability standard [29].

for a maximum discharge of blood and imperfect bleeding to keep most of the blood in the carcass. In accordance with the observations of several authors, we can see that these two tests can show a difference between the quality of the colour of perfectly bled poultry and that of imperfectly bled one.

Residual blood in poultry carcasses is responsible for high values of the colour parameters $\left(L^{*} A^{*} B^{*}\right)$ compared with the perfectly bled samples and therefore the deterioration of the quality of poultry.

This justifies that excessive bleeding caused by different techniques of stunning and non-perfect slaughtering increase haemoglobin, and increases the pHu level of carcasses especially in case of increasing the storage temperature and in the hot season. Reducing the $\mathrm{pHu}$ level of carcasses would be absolutely possible by applying good slaughter practices without stunning and with storage below.

Carcasses with less residual blood have lower values of the colour parameters $\left(L^{*} A^{*} B^{*}\right)$ and lower values of the pHu compared with the imperfectly bled samples and therefore a better quality.

\section{REFERENCES}

[1] J. W. Gunstone, "Using Blood Plasma," The National Provisioner, Chicago, 1980, p. 26.

[2] T. P. Yorks, G. M. Ward and D. A. Cramer, "Energy Considerations in Translating Cattle in into Edible Beef," Food Technology, Vol. 34, No. 5, 1980, p. 54.

[3] R. A. Lawrie, “Meat Science,” Pergamon Press, New York, 1979.

[4] G. W. Newell and C. S. Shaffner, "Blood Lost by Chickens during Killing,” Poultry Science, Vol. 29, No. 2, 1950, pp. 271-275. doi:10.3382/ps.0290271

[5] P. D. Warriss, "The Quantitative Determination of Hemoglobin in Ovine Muscles,” Analytical Biochemistry, Vol. 72, No. 1-2, 1976, pp. 104-112. doi:10.1016/0003-2697(76)90511-X

[6] C. Z. Alvarado, M. P. Richards, S. F. O’Keefe and H. Wang, "The Effect of Blood Removal on Oxidation and 
Shelf Life of Broiler Breast Meat,” Poultry Science, Vol. 86, No. 1, 2007, pp. 156-161.

[7] A. A. Dunn, D. J. Kilpatrick and N. F. S. Gault, "Influence of Ultimate $\mathrm{pH}$, Sarcomere Lengthand Cooking Loss on the Textural Variability of Cooked M. Pectoralis Major from Free Range and Standard Broilers," British Poultry Science, Vol. 34, No. 4, 1993, pp. 663-675. doi:10.1080/00071669308417625

[8] D. P. Cornforth, “Color and Its Importance,” In: A. M. Pearson and T. R. Dutson, Eds., Quality Attributes and Their Measurement in Meat, Poultry, and Fish Products, Chapman and Hall, London, 1994, pp. 34-78. doi:10.1007/978-1-4615-2167-9_2

[9] J. K. Northcutt, E. A. Foegeding and F. W. Edens, "Water-Holding Properties of Thermally Preconditioned Chicken Breast and Leg Meat,” Poultry Science, Vol. 73, No. 2, 1994, pp. 308-316. doi:10.3382/ps.0730308

[10] C. D. Allen, S. M. Russell and D. L. Fletcher, "The Relationship of Broiler Breast Meat Colour and $\mathrm{pH}$ to Shelf Life and Odour Development,” Poultry Science, Vol. 76, No. 7, 1997, pp. 1042-1046.

[11] S. Barbut and G. S. Mittal, "Effects of pH on Physical Properties of White and Dark Turkey Meat," Poultry Science, Vol. 72, No. 8, 1993, pp. 1557-1565. doi:10.3382/ps.0721557

[12] S. Barbut, "Estimates and Detection of the PSE Problem in Young Turkey Breast Meat," Canadian Journal of Animal Science, Vol. 76, No. 3, 1996, pp. 455-457. doi:10.4141/cjas96-066

[13] D. L. Fletcher, "Broiler Breast Meat Color Variation, pH, and Texture,” Poultry Science, Vol. 78, No. 9, 1999, pp. 1323-1327.

[14] R. L. J. M. Van Laack, C. H. Van Liu, M. O. Smith and H. D. Loveday, "Characteristics of Pale, Soft, Exudative Broiler Breast Meat,” Poultry Science, Vol. 79, No. 7, 2000, pp. 1057-1061.

[15] C. Berri, N. Warcrenier, N. Millet and E. Le Bihan-Duval, "Effect of Selection Forimproved Body Composition on Muscle and Meat Characteristics of Broilers from Experimental and Commercial Lines," Poultry Science, Vol. 80, No. 7, 2001, pp. 833-838.

[16] R. G. D. Steel, J. H. Torrie and D. A. Dicky, "Principles and Procedures of Statistics: A Biometrical Approach," 3rd Edition, McGraw Hill Book Co. Inc., New York, pp. 352-358.

[17] F. J. G. Schreurs, "Post Mortem Changes in Cicken Muscle,” Ph.D. Thesis, Wageningen Agricultural University,
Wageningen, 1999.

[18] Hess, "The Residual Blood Content of Meat: A Review," Journal of the Science of Food and Agriculture, Vol. 28: 1968, p. 457.

[19] M. Qiao, D. L.Fletcher, D. P.Smith and J. K. Northcutt, "The Effect of Broiler Breast Meat Color on $\mathrm{pH}$, Moisture, Water-Holding Capacity, and Emulsification Capacity,” Poultry Science, Vol. 80, No. 5, 2001, pp. 676-680.

[20] M. E. Nairn, "Carcass Downgrading in Broiler Chickens,” British Poultry Science, Vol. 25, 1984, pp. 441-446. doi:10.1080/00071668408454885

[21] U. Gotze and P. D. Wariss, "The Residual Content of Meat: A Review," Journal of the Science of Food and Agriculture, Vol. 28, 1977, p. 457.

[22] G. Heinz and P. D. Wariss, "The Residual Blood Content of Meat: A Review," Journal of the Science of Food and Agriculture, Vol. 28, 1977, p. 457.

[23] R. A. Lawrie, “Meat Science,” Pergamon Press, New York, 1977.

[24] D. L. Fletcher, "Relationship of Breast Meat Color Variation to Muscle pH and Texture,” Poultry Science, Vol. 74, No. 1, 1995, p. 120.

[25] F. Abeni and G. Bergoglio, "Characterization of Different Strains of Broiler Chicken by Carcass Measurements, Chemical and Physical Parameters and NIRS on Breast Muscle,” Meat Science, Vol. 57, No. 2, 2001, pp. 133-137. doi:10.1016/S0309-1740(00)00084-X

[26] C. Berri, N. Wacrenier, N. Millet and E. Le Bihan-Duval, "Effect of Selection for Improved Body Composition on Muscle and Meat Characteristics of Broilers from Experimental and Commercial Lines," Poultry Science, Vol. 80, No. 7, 2001, pp. 833-838.

[27] J. Culioli, C.Touraille, P. Bordes and J. P. Girard, “Inventory of Quality Problems Currently Faced Chicken Fillets in French Slaughterhouses,” Arch Geflugelk, Vol. 53, 1990, pp. 237-245.

[28] V. Gigaud, E. Casenave, T. Bordeau, E. Baeza and C. Berri, "Inventory of Quality Problems Currently Faced Chicken Fillets in French Slaughterhouses," Journal of 13th Muscle Science and Technology, Special Issue, 2010 p. 216.

[29] J. Zanusso, H. Rémignon, A. Auvergne, C. Molette, H. Manse and R. Babilé, "Zootechnical Characteristics and Qualities of Chicken Meat,” Quatrième Journées de la Recherche Avicole, Nantes, pp. 269-272. 